\title{
Using Primers of Random Amplification Polymorphism DNA (RAPD) in Molecular Identification of Peach Cultivars Prunus persica (L.) Batsch Rosaceae
}

\author{
Bassam H. A. AL Jumeily 1*, 2 Aamer M. M. Almaathidy \\ $1^{*}$ Department of Biology Education Faculty for Pure Science, University of Kirkuk, Kirkuk, Iraq \\ ${ }^{2}$ Department of Biology, College of Education for Pure Science, University of Mosul, Mosul, Iraq \\ E. Mail ${ }^{1^{*}} \underline{\text { dr.bassamaljumeily@gmail.com, }}{ }^{2}$ dr.aamer@unmosul.edu.iq
}

(Received April 05, 2021; Accepted June 25, 2021; Available online August 28, 2021)

DOI: 10.33899/edusj.2021.168641, (C) 2021, College of Education for Pure Science, University of Mosul.

This is an open access article under the CC BY 4.0 license (http://creativecommons.org/licenses/by/4.0/).

\begin{abstract}
The present study includes identification of (9) cultivars of the species Prunus persica (L.) Batsch. Which were Early Grand, Babcock, Giant Babcock, Mammoth, Elberta, Cardinal , Blanko, Novadona , and Transvalia cultivated in Ninevah \ Iraq by using random genetic primers in amplification polymorphic DNA (RAPD). (9) random primers were used and amplifications were deported within the agrose . The results showed that the amount of the nucleic acid ranged between $(20-25) \mu \mathrm{g} / \mathrm{ml}$ of the leaves extract and reactions of the randomly amplification were carried out with (9) primers, all of them migrated within agarose gel, and generated an amplified bands of DNA. The results have admitted to the Computer and analyzed using private statistical program PAST. The results have showed that the genetic discrepancy value reached (0.7264) in Transvalia cultivar whereas the minimum value of the genetic variant reached to $(0.108)$ in the cultivar Cardinal. The dendrogram was also showed that the cultivar Babcock, Giant Bacock, Transvalia and Novadona were the most similar to each other, whereas cultivars Cardinal was the most variant from the other cultivar studies.
\end{abstract}

Keywords: Prunus persica, varieties, RAPD markers.

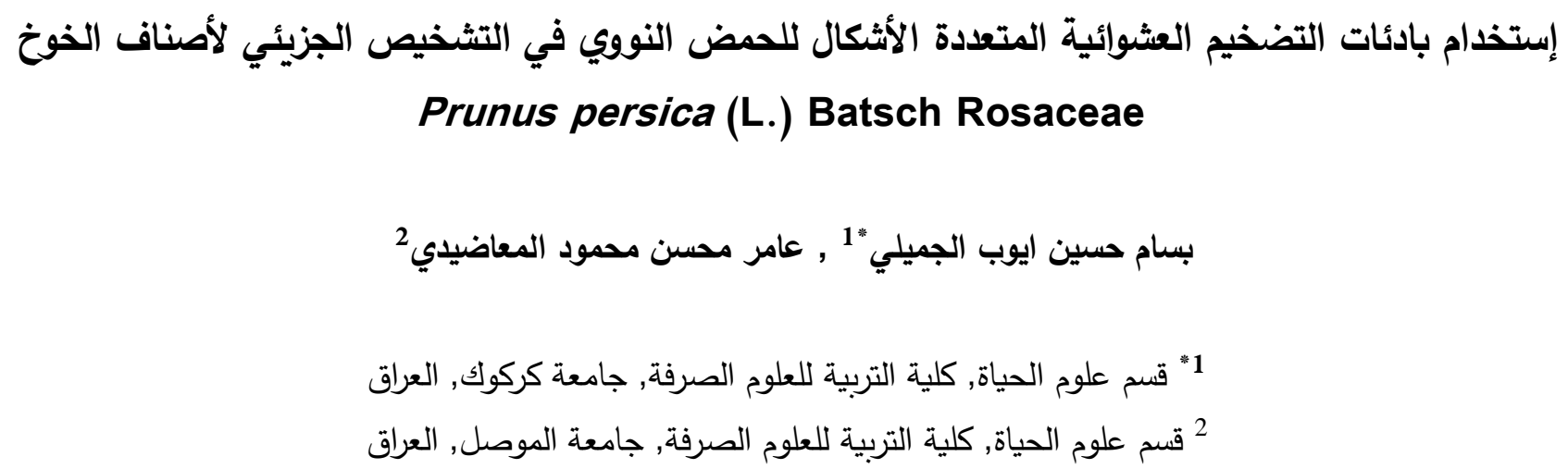


Journal of Education and Science (ISSN 1812-125X), Vol: 30, No: 3, 2021 (104-116)

Special Issue for Proceeding of $3^{\text {rd }}$ National (1'st international conference of biology) (ICBSUM 2021) 5, 6 July

College of Education for Pure Science, University of Mosul, Mosul, Iraq.

الخلاصة

تضمن البحث الحالي تثخيص (9) أصناف من الخوخ Prunus persica (L.) وهي الصنف المبكر Early Grand ، بابكوك Pabcock ، جيانت بابكوك Giant Babcock، ماموث Mammoth، البرتا Clberta، كاردينال Cardinal، ترانسفاليا Transvalia، نوفادونا Blanko والبلانكو Novadona المستزرعة في محافظة نينوى / العراق ، بأستخدام تقنية التضخيم العشوائية المتعدد للحمض النووي Random amplification polymorphic DNA) RAPD) , إذ استخدمت (9) بادئات عشوائية وتم ترحيل نواتج التضخيم

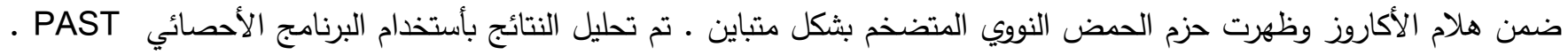
اوضحت نتائج الدراسة أن تركيز الحمض النووي المستخلص تراوحت بين (20- 25) مايكروغرام / مل ، اضافة لإمكانية فصل الأصناف له عن بعضها البعض وتحديد درجة التباين الوراثي بينها، حيث أن اعلى قيمة في التباين الوراثي كانت (0.7264) في صنف الترانسفاليا واقل قيمة في صنف كاردينال كانت (0.10811)، فيما أظهر المخطط الثجيري Dendrogram أن الأصناف (بابكوك ، جيانت بانكوك، الترانسفاليا ، نوفادونا) كانت الأكثر تثابها مع بعضها البعض، اما الصنف كاردينال كان الأكثر تباينا عن باقي الأصناف المدروسة. الكلمات المفتاحية: الخوخ Prunus persica ، الأصناف ، التضخيم العشوائي.

المقدمة

ينتمي الخوخ Prunus persica (L.) Batsch الى جنس Prunus والى العويئلة Prunoideae التابع الى العائلة الوردية Rosaceae، ويشكل مكانة مميزة بين اشجار الفاكهة ذات الثمار الحجرية Stone fruits إذ تعد ثماره من الثمار اللوزية المهمة والمرغوب فيها [1] وذات اهمية اقتصادية في العالم، إذ أنها تتتج بمعدلات عالية لأجل إستهلاك وإستخدام ثمارها الطازجة ـ وتعد اوربا اكثر مناطق العالم في انتاج الخوخ اذ تقدر نسبة إنتاجها حوالي 49\% تليها الولايات المتحدة ثم أسيا وهي بهذا تأتي بعد التفاح بالمرتبة الثانية من حيث الانتاج [2]. فضلا عن بعض الأصناف المهنة Hybrid cultivars تستخدم كنباتات زينة بسبب وفرة اوراقها وازهارها بجانب ثمارها واشكالها وروائحها الزكية [3].

على الصعيد العالمي فقد أجريت عدة بحوث على أصناف الخوخ في مجال تشخيصها خصوصا في ظل ظهور التقانات الحيوية اصبحت دراسة التتوع الحيوي اكثر اهمية ودقة فقد استخدمت تقانة الـ RAPD في عدد من الدراسات في مجال توصيف المصادر الوراثية النباتية، ففي دراسة قام بها [4] إذ اشارا إلى أن البادئات الوراثية تستخدم بنجاح في التشخيص والتتوع الوراثي بين الأصناف المتداخلة وتوضيح التشابهات الوراثية وتعطي أشارات عن عملية التهجين وأن التشخيص الجزيئي ذات أهمية بشكل خاص مع أشجار الفاكهة التي تتميز بححتوى عال من التغاير او التعدد .

كما ساعدت هذه التقانة في تقييم التنوع الوراثي بين (28) صنفا من الخوخ خلا استخدام (12) بادئة حيث بلغ عدد الحزم ذات التعددية الشكلية (81) حزمة وتراوحت درجة الاختلاف الوراثي للأصناف المدروسة بين 5-50\% , [3]. وفي دراسة أخرى استخدمت تقانة الـ (RAPD) في دراسة العلاقات الوراثية بين (19) صنفا من اللوز Almond من خلال استخدام (40) بادئة، وقد أوضحت الدراسة أن معدل الاختلاف الوراثي بين الأصناف كان محدودا وتراوحت درجة التثابه بين 70-90\% [5] . وأوضح أنه تم اجراء تحاليل 
Journal of Education and Science (ISSN 1812-125X), Vol: 30, No: 3, 2021 (104-116)

Special Issue for Proceeding of $3^{\text {rd }}$ National (1'st international conference of biology) (ICBSUM 2021) 5, 6 July

College of Education for Pure Science, University of Mosul, Mosul, Iraq.

الـ(RAPD) لدراسة العلاقة الوراثية بين (9) اصناف من الكمثرى المستزرعة بأستخدام (22) بادئة حيث بلغ عدد الحزم الناتجة (358)

حزمة منها (327) ذات تعددية شكلية في حين بلغت درجة التثابه بين الأصناف 63\% [6] ـ كما تمت الاستفادة من تقانة الـ (RAPD) في العديد من النباتات والمحاصيل حيث استخدمت في تقييم التتوع الوراثي في التفاح [7] والتوت [8] والخوخ [10] فضلا عن عدد كبير من المحاصيل الأخرى واستخدمت هذه التقانة بثكل خاص في الجنس Prunus (L.) في انثاء الخرائط الجينية وفي دراسة التنوع الوراثي لأصول واصناف تابعة لهذا الجنس [11] .

بعد تطور زراعة الخوخ في السنوات الأخيرة في العراق، قامت وزارة الزراعة بإدخال اصناف جديدة تم زراعتها وفق برنامج خاص وتكليف محطات البستتة والغابات في المحافظات بإنتاج شتلات لزراعتها، ومن هذا المنطلق يهدف البحث الحالي الى تشخيص هذه الاصناف و تحديد التنوع الوراثي لها بإعتماد تقنية التضخيم العشوائية المتعدد للحمض النووي RAPD.

Materials and methods مواد وطرائق العمل

Plant material المادة النباتية

جمعت العينات الورقية النباتية الحديثة العمر للاصناف قيد الدراسة والخالية من الاصابات المرضية والحشرية المستزرعة في محطة البستتة والغابات في مدينة الموصل العراق ومن ثلاثة اشجار لكل صنف، وغسلت جيدا بالماء المقطر ثم وضعت داخل اكياس ورقية مثقبة وتركت العينات حتى جفت تماما لحين الاستعمال.

2- استخلاص الحمض النووي ( DNA Extraction )

عزلت المادة الوراثية الـNA من أوراق اصناف الخوخ اليافعة الجافة حيث جمعت (5- 10) اوراق من كل صنف على حدة وغسلت عدة مرات بالماء المقطر • وعزل الـNA حسب طريقة [12 ; 13] وتم حساب تركيزه التي كانت بحدود (20-25) مايكروغرام / مل , أما نقاوته تراوحت بين $(1,8-6)$ والتي تم تحديدها بالاعتماد على قياس الكثافة الضوئية بأستخدام جهاز قياس القطرة المتتاهية Nano drop عند الطول الموجي 280-260 نانوميتر ، بعدها تم ترحيل 5 مايكروليتر من الحمض النووي المعزول ضمن هلام الاكاروز بتركيز 0.8\% الثكل (1). 


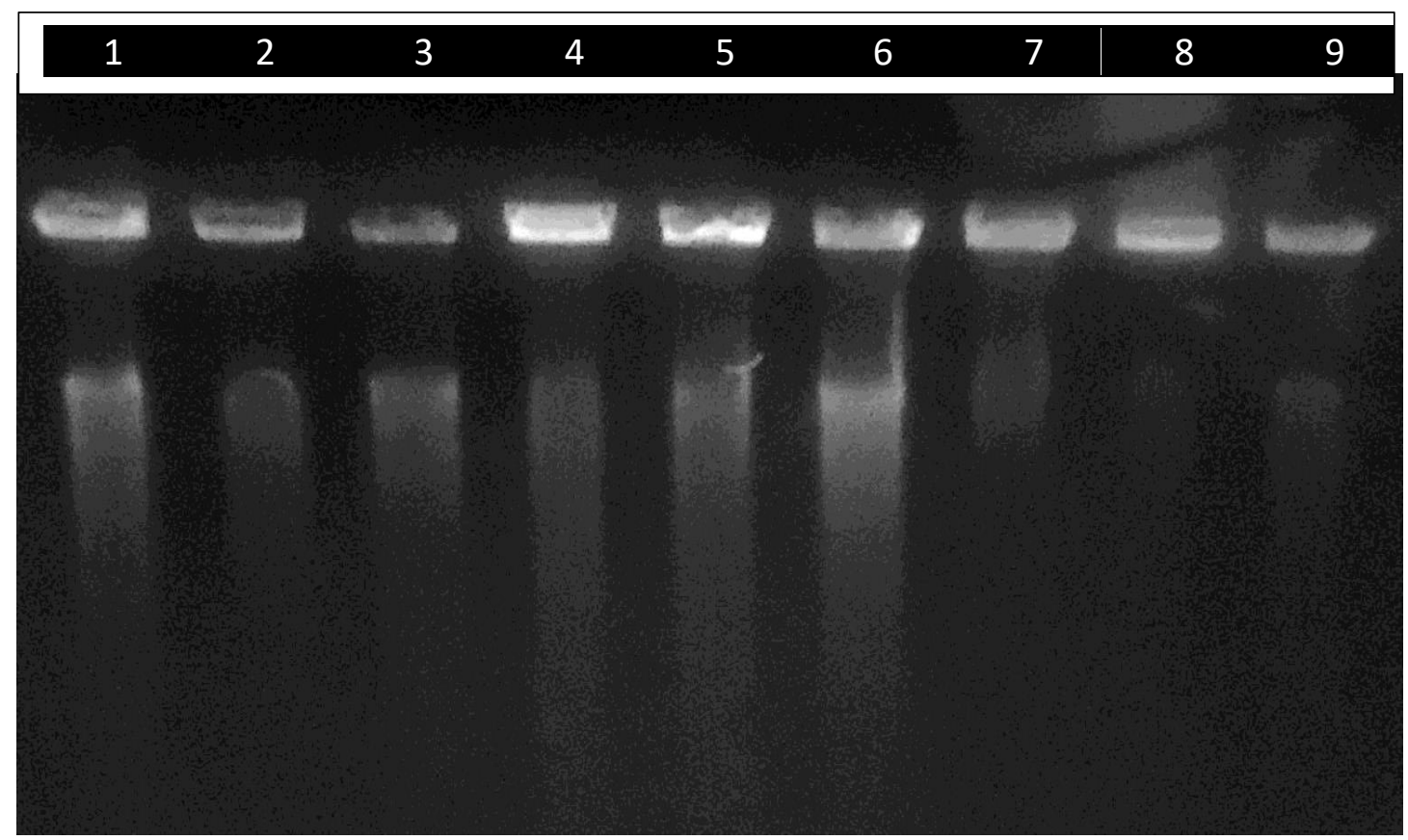

الثكل (1): الحمض النووي الجينومي DNA و المعزول من أصناف الخوخ Persica . pera المدروسة والمسار ات

1. Babcock 2. Giant Babcok 3. Novadona 4. Early Grand 5. Blanko 6. Elberta 7.Transvalia 8.Mammoth 9.Cardinal.

DNA Analysis الدليل عينات

أُستخدمت (9) بادئات للتضخيم العشوائي المجهزة من قبل شركة Bioneer الكورية المنشأ والمثبتة تسلسلاتها (قواعدها النتروجينية) جدول (1) وتم تحديد حجوم وتراكيز مكونات مزيج التضخيم وفقا لتعليمات الشركة المجزة واجريت تفاعلات التضخيم العشوائي حسب ما ذكره [14] على عينات الحمض النووي DNA المعزولة من أصناف الخوخ المدروسة، ثم اجريت عملية الترحيل على هلام الاكاروز - UV وصبغت بصبغة بروميد الايثديوم لمدة (20- 30) دقيقة ثم عرضت الهلامة لمصدر الأشعة فوق البنفجية من نوع Transiluminator الدليل الحجمي القياسي DNA Ladder.

\section{Statistical analysis التحليل الاحصائي}

تم تحليل البيانات الناتجة عن تفاعل البادئات بإختبارات الـ (RAPD) والتي ظهرت على هلام الاكاروز وذلك بإعطاء الرمز (1) لوجود الحزمة والرمز (0) لعدم وجودها وتم ترتيبها بشكل جدول متسلسل ثم تحويل جميع البيانات إلى قيم التشابه الوراثي بأستخدام معامل التقارب لئل والتباعد [15] واستخدم البرنامج الاحصائي Numerical Taxonomy and Multivar Analysis System وتم تحديد معامل التباعد 


\section{Journal of Education and Science (ISSN 1812-125X), Vol: 30, No: 3, 2021 (104-116) \\ Special Issue for Proceeding of $3^{\text {rd }}$ National (1st international conference of biology) (ICBSUM 2021) 5, 6 July College of Education for Pure Science, University of Mosul, Mosul, Iraq.}

الوراثي باستخدام التحليل العنقودي Cluster multivariate وفق طريقة الوسط الحسابي للمجموعات الزوجية غير الموزونة (UPGMA ) Unweighted Pair Group Mean Average التباعد الوراثي الذي يجسد العلاقة الوراثية بين هذه الأصناف وتم حساب النسبة المئوية لكفاءة البادئ من خلال تحويل وجود او غياب

$$
\text { الحزم المتباينة (0,1) من خلال المعادلة التالية: }
$$

كفاءة البادئ = العدد الكلي لحزم البادئ / العدد الكلي لحزم كل البادئات × 100\%

أما القدرة التمييزية لكل مؤشر فقد تم تحديدها وفق المعادلة الاتية:

القدرة التمييزية \% =عدد الحزم المتباينة للبادئ / عدد الحزم المتباينة لكل البادات 100

Results النتائج

استخدمت تفاعلات RAPD في دراسة العلاقات الوراثية بين أصناف الخوخ المدروسة حيث يوضح الجدول (1) والثكل (2) عدد

البادئات المستخدمة في الدراسة وتسلسل القواعد النتروجينية فيها وعدد الحزم المتباينة والكلية وكفاءة البادئ والقدرة التمييزية له الناتجة عن تضخيم الـ DNA و تبعا لتتابع القواعد النيتروجينية للبادئات العشوائية المستخدمة لأصناف الخوخ قيد الدراسة. أظهرت نتائج التضخيم العشوائي للحمض النووي (DNA) حزم متباينة polymorphic bands وحزم فريدة (مميزة) unique bands , إذ بينت النتائج دور واضح لبعض البادئات في تحديد التباعد أو التباين الوراثي للأصناف المدروسة. حيث أظهر البادئ 13-OPH حزم متباينة للأصناف

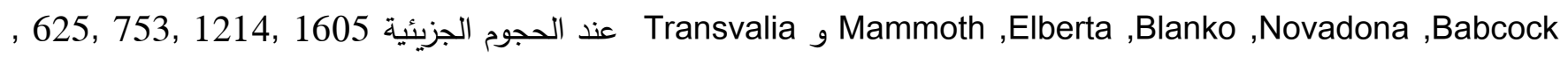
510 زوج قاعدي على التوالي , في حين لم تظهر أي نواتج للتضخيم ضمن هلام الأكاروز المصطبخ ببروميد الاثيديوم الأحمر للأصناف Giant Babcok, Early Grand,Cardinal 100\% ـ أما القدرة التمييزية لهذا البادئ فتم تحديدها اعتمادا على عدد الحزم التي أظهرها بالنسبة للمجموع الكلي للحزم المتباينة التي أظهرتها البادئات الأخرى كانت 12.9\% أما كفاءتها النسبية فقد بلغت 11.8\% بناءا على عدد الحزم الكلية التي أظهرها ، اما البادئ

Novadona , Giant Babcok , Babcock وجد فيه مواقع خاصة لارتباطه ضمن الحمض النووي للأصناف OPH - 14 Mammoth و Mlberta , Transvalia Early Grand 848 , 528 و 352 زوج قاعدي على التوالي , في حين أنه لم يرتبط عند أي موقع للحمض النووي للأصناف , Cardinal,, Blanko التباين 100\% وقدرته التمييزية 18.2 في حين بلغت الكفاءة النسبية لهذا البادئ 16.6\% , تميز هذا البادئ بأنه أظهر أكبر عدد من الحزم المتضخمة من بين البادئات المستخدمة في هذه الدراسة واستطاع تمييز الأصناف Cardinal , Early Grand , Blanko بعدم إمتلاكه مواقع متممة أو مكملة له ضمن الحمض النووي للأصناف الثلاثة ـ أما البادئ 17 - OPH فتميز بقلة المواقع التي إرتبط بها ضمن الحمض النووي للأصناف المدروسة إذ أظهر هلام الأكاروز المصطبخ ببروميد الإثيديوم الأحمر عند تعريضه لمصدر الأشعة فوق

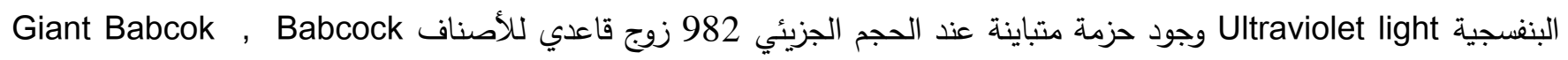


Journal of Education and Science (ISSN 1812-125X), Vol: 30, No: 3, 2021 (104-116)

Special Issue for Proceeding of $3^{\text {rd }}$ National (1 $1^{\text {st }}$ international conference of biology) (ICBSUM 2021) 5, 6 July

College of Education for Pure Science, University of Mosul, Mosul, Iraq.

Elberta ,Transvalia , Novadona , Early Grand , Blanko عند الحجم الجزيئي 397 زوج قاعدي للأصناف Novadona , Blanko , Babcock و Transvalia مقارنة ببقية الاصناف قيد الدراسة وبلغ العدد الكلي للحزم المتضخمة حزمتين فقط وبلغت نسبة التباين 100\% أما قدرته التمييزية فقد بلغت 10\% وكفاءته 9.1\% , تميز هذا البادئ بأنه أظهر أقل عدد من الحزم المتضخمة إذ بلغ عددها 2 حزمة واستطاع هذا البادئ تمييز الصنفين Mammoth و Cardinal

جدول (1) عدد الدزم المتباينة والكلية ونسبة تباين وكفاءة البادئات العشوائية والقدرة التمييزية

\begin{tabular}{|c|c|c|c|c|c|c|c|}
\hline (زوج قاعدي) & التباديزيزة التئية & $\begin{array}{c}\text { كفاءة } \\
\text { البادئ } \\
\text { \% }\end{array}$ & $\begin{array}{c}\text { نسبة } \\
\text { \% }\end{array}$ & الكزد & عدد الحزم & تسلسل القواعد النتروجينية في & البادئات \\
\hline $982-397$ & 10 & 9.1 & 100 & 17 & 17 & CAC TCT СCТC & $\mathrm{OPH}-17$ \\
\hline$\sim 2000-352$ & 18.2 & 16.6 & 100 & 31 & 31 & ACC AGG TTGG & $\mathrm{OPH}-14$ \\
\hline $1605-510$ & 12.9 & 11.8 & 100 & 22 & 22 & GAA TGG GCCA & $\mathrm{OPH}-13$ \\
\hline 984-905 & 7.6 & 7.4 & 92.8 & 14 & 13 & CAG GCCC TC & $\mathrm{OPA}-1$ \\
\hline $1705-183$ & 11.2 & 12.3 & 82.6 & 23 & 19 & TGC CGA CCTG & $\mathrm{OPA}-2$ \\
\hline $1620-70$ & 12.9 & 17.1 & 68.8 & 32 & 22 & AAT CGG GCTG & $\mathrm{OPA}-4$ \\
\hline $793-308$ & 8.3 & 8 & 93.3 & 15 & 14 & GAA TGG GCCA & OPA -13 \\
\hline $689-263$ & 9.4 & 8.6 & 100 & 16 & 16 & CAC AGC GACA & OPW -13 \\
\hline $970-310$ & 9.4 & 9.1 & 94.1 & 17 & 16 & CTG ATG CGTC & OPW-11 \\
\hline- & $\% 100$ & $\% 100$ & - & 187 & 170 & & المجموع \\
\hline
\end{tabular}

واظهر البادئ 1 - OPA حزمة متباينة للأصناف OPanko , Novadona و Transvalia عند الحجوم الجزيئية 617 , 984 , 325 زوج قاعدي والأصناف Mransvalia , Blanko , Novadona و عismmoth عند الحجم الجزيئي 242 زوج قاعدي , في حين أنه إرتبط بموقع فريد للصنف Cardinal عند الحجم الجزيئي 905 زوج قاعدي وبذلك استطاع هذا البادئ من تمييز الصنف Cardinal من خلال هذا الإرتباط , كما إستطاع تمييز الأصناف Early Grand, Giant Babcok , Babcock و Elberta لعدم إمتلاكه مواقع مكملة له ضمن الحمض النووي لهذه الأصناف وكان العدد الكلي للحزم المضاعفة الناتجة 4 حزم وبلغت نسبة التباين 92.8\% أما قدرته التمييزية بلغت 7.6\% وبكفاءة 7.4 \% الجدول (2). 
Journal of Education and Science (ISSN 1812-125X), Vol: 30, No: 3, 2021 (104-116)

Special Issue for Proceeding of $3^{\text {rd }}$ National (1st international conference of biology) (ICBSUM 2021) 5, 6 July College of Education for Pure Science, University of Mosul, Mosul, Iraq.

جدول (2) الحزم المتضخمة مع أحجامها الجزيئية للبادئات (OPH-13, OPH-14, OPH-17, OPA-13, OPA-1)

\begin{tabular}{|c|c|c|c|c|c|c|c|c|c|c|c|}
\hline نوع الحزمة & الحجم الجزيئي ( زوج & \multicolumn{9}{|c|}{ الأصناف } & 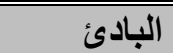 \\
\hline \multirow{6}{*}{ متعدد الأحجام } & 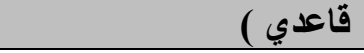 & 1 & 2 & 3 & 4 & 5 & 6 & 7 & 8 & 9 & \multirow{6}{*}{ OPH-13 } \\
\hline & 1605 & 1 & 0 & 1 & 0 & 1 & 1 & 1 & 1 & 0 & \\
\hline & 1214 & 1 & 0 & 0 & 0 & 1 & 1 & 1 & 1 & 0 & \\
\hline & 753 & 0 & 0 & 0 & 0 & 1 & 1 & 0 & 1 & 0 & \\
\hline & 625 & 1 & 0 & 0 & 0 & 1 & 1 & 1 & 1 & 0 & \\
\hline & 510 & 1 & 0 & 1 & 0 & 0 & 0 & 1 & 0 & 0 & \\
\hline \multirow{9}{*}{ متعدد الأحجام } & More than 2000 & 1 & 1 & 1 & 0 & 0 & 1 & 1 & 0 & 0 & \multirow{9}{*}{ OPH-14 } \\
\hline & 1715 & 1 & 1 & 1 & 0 & 0 & 1 & 1 & 0 & 0 & \\
\hline & 1300 & 1 & 1 & 0 & 0 & 0 & 0 & 0 & 0 & 0 & \\
\hline & 1025 & 1 & 1 & 0 & 0 & 0 & 1 & 1 & 0 & 0 & \\
\hline & 973 & 1 & 1 & 1 & 0 & 0 & 1 & 1 & 0 & 0 & \\
\hline & 845 & 1 & 1 & 1 & 0 & 0 & 0 & 0 & 0 & 0 & \\
\hline & 688 & 0 & 1 & 0 & 0 & 0 & 0 & 0 & 1 & 0 & \\
\hline & 528 & 1 & 1 & 0 & 0 & 0 & 0 & 1 & 1 & 0 & \\
\hline & 352 & 0 & 0 & 0 & 0 & 0 & 0 & 1 & 1 & 0 & \\
\hline \multirow[b]{2}{*}{ متعدد الأحجام } & 982 & 1 & 1 & 1 & 1 & 1 & 1 & 1 & 0 & 0 & \multirow[b]{2}{*}{ OPH-17 } \\
\hline & 397 & 1 & 0 & 1 & 0 & 1 & 0 & 1 & 0 & 0 & \\
\hline \multirow{3}{*}{ متعدد الأحجام } & 689 & 0 & 0 & 1 & 1 & 1 & 0 & 1 & 0 & 0 & \multirow{3}{*}{ OPW-13 } \\
\hline & 361 & 0 & 0 & 1 & 1 & 1 & 1 & 1 & 1 & 0 & \\
\hline & 263 & 0 & 0 & 1 & 1 & 1 & 1 & 1 & 1 & 1 & \\
\hline \multirow{4}{*}{ متعدد الاحجام } & 984 & 0 & 0 & 1 & 0 & 1 & 0 & 1 & 0 & 0 & \multirow{5}{*}{ OPA-1 } \\
\hline & 617 & 0 & 0 & 1 & 0 & 1 & 0 & 1 & 0 & 0 & \\
\hline & 325 & 0 & 0 & 1 & 0 & 1 & 0 & 1 & 0 & 0 & \\
\hline & 242 & 0 & 0 & 1 & 0 & 1 & 0 & 1 & 1 & 0 & \\
\hline فريدة (مميزة) & 905 & 0 & 0 & 0 & 0 & 0 & 0 & 0 & 0 & 1 & \\
\hline
\end{tabular}

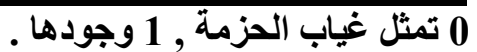

جاءت نتائج البادئ 13 - مقاربة لنتائج البادئ السابق من حيث ضئآلة مواقع الإرتباط ضمن الحمض النووي لأصناف الخوخ

قيد الدراسة حيث أظهر حزمة عند الحجم الجزيئي 689 زوج قاعدي للأصناف Blanko, Early Grand, Novadona و وعند الحجم الجزيئي 361 زوج قاعدي للأصناف Mransvalia , Elberta , Blanko , Early Grand, Novadona و Mammoth بالإضافة الى الأصناف Mammoth , Transvalia , Elberta , Blanko , Early Grand, Novadona و الجزيئي (263) زوج قاعدي وبلغ العدد الكلي للحزم المتضخمة 3 وبلغت نسبة التباين 100\% وقدرته التمييزية 9.4\% وكفاءته \% 8.6 م في حين أن البادئ 2 - و فيه العديد من مواقع الارتباط عدا الصنفين Eavadona و فقد أظهر هلام الأكاروز حزمة متباينة للأصناف السبعة الباقية قيد الدراسة عند الحجوم الجزيئية 110,415,445,670,978, 1208, 1705 زوج قاعدي على التوالي من ناحية أخرى اظهر هذا البادئ حزمة فريدة (مميزة) للصنف Blanko عند الحجوم الجزيئية 1314 , 183 , 913 زوج قاعدي كذلك للصنف Babcock عند الحجم الجزيئي 314 زوج قاعدي , واستطاع هذا البادئ تمييز الصنفين Novadona 
Journal of Education and Science (ISSN 1812-125X), Vol: 30, No: 3, 2021 (104-116)

Special Issue for Proceeding of $3^{\text {rd }}$ National (1 ${ }^{\text {st }}$ international conference of biology) (ICBSUM 2021) 5, 6 July College of Education for Pure Science, University of Mosul, Mosul, Iraq.

و Early Grand في عدم إمتلاكه مواقع مكملة له ضمن الحمض النووي لهذين الصنفين , كما إستطاع تمييز الصنفين Babcock و Blanko من خلال الحزم الفريدة (المميزة) التي أظهرها هذا البادئ وبلغ العدد الكلي للحزم المتضخمة الناتجة عن إستخدامه 5 حزم إذ كانت نسبة التباين 62.6 \% وبلغت والقدرة التمييزية 11.2\% وكفاءته \% 12.3 ـ أما البادئ 13-OPA أظهر مواقع إرتباط ضئيلة ضمن الحمض النووي للأصناف قيد الدراسة ليعطي حزمة فريدة (مميزة) عند الحجم الجزيئي 793 زوج قاعدي للصنف Elberta وحزم متباينة في جميع الأصناف المدروسة باستثناء هذا الصنف إذ أظهر هذا البادئ حزما عند الحجمين الجزيئين 428 و 308 زوج قاعدي على التوالي وبذا ميز هذا البادئ الصنف Cardinal لعدم إمتلاكه مواقع متممة له ضمن الحمض النووي له وبلغ العدد الكلي للحزم الناتجة من هذا البادئ 3 , أما نسبة التباين فكانت \% 93.3 والقدرة التمييزية 8.3\% وكفاءته 8\% كما اظهر البادئ 11 مئع-OPW حزمة

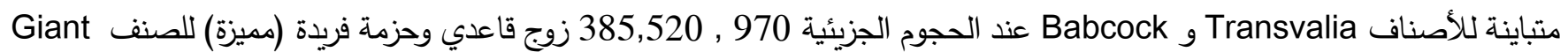
Babcock Mammoth و و Cardinal ومي عدم امتلاكه مواقع متممة لله ضمن الحمض النووي لهذين الصنفين ـ أما نسبة التباين لهذا البادئ كانت 94.1 وقدرته التمييزية 9.4\% وبكفاءة 9.1\% الجدول (3) .

جدول (3): الحزم المتضخمة مع أحجامها الجزيئية للبادئات ( OPW-11 , OPA-13 , OPA-2 )

\begin{tabular}{|c|c|c|c|c|c|c|c|c|c|c|c|}
\hline نوع الحزمة & الحجم الجزيئي ( زوج & \multicolumn{9}{|c|}{ الأصناف } & البادئ \\
\hline \multirow{8}{*}{ متعدد الأحجام } & قاعدي ) & 1 & 2 & 3 & 4 & 5 & 6 & 7 & 8 & 9 & \multirow{12}{*}{ OPA-2 } \\
\hline & 1705 & 1 & 1 & 1 & 1 & 0 & 0 & 0 & 0 & 0 & \\
\hline & 1208 & 0 & 1 & 0 & 1 & 0 & 0 & 0 & 0 & 1 & \\
\hline & 978 & 1 & 1 & 1 & 1 & 0 & 0 & 0 & 0 & 0 & \\
\hline & 670 & 0 & 0 & 0 & 0 & 0 & 0 & 0 & 1 & 1 & \\
\hline & 445 & 1 & 0 & 0 & 0 & 0 & 0 & 0 & 0 & 1 & \\
\hline & 415 & 1 & 0 & 0 & 0 & 1 & 0 & 0 & 0 & 0 & \\
\hline & 110 & 1 & 0 & 0 & 0 & 0 & 0 & 0 & 0 & 1 & \\
\hline \multirow{4}{*}{ فريدة (مميزة) } & 1314 & 0 & 0 & 0 & 0 & 1 & 0 & 0 & 0 & 0 & \\
\hline & 913 & 0 & 0 & 0 & 0 & 1 & 0 & 0 & 0 & 0 & \\
\hline & 314 & 0 & 0 & 0 & 0 & 0 & 0 & 0 & 0 & 1 & \\
\hline & 183 & 0 & 0 & 0 & 0 & 1 & 0 & 0 & 0 & 0 & \\
\hline \multirow[t]{2}{*}{ متعدد الأحجام } & 428 & 1 & 1 & 1 & 1 & 1 & 1 & 0 & 1 & 0 & \multirow{3}{*}{ OPA-13 } \\
\hline & 308 & 1 & 1 & 1 & 1 & 1 & 1 & 1 & 0 & 0 & \\
\hline فريدة (مميزة) & 793 & 0 & 0 & 0 & 0 & 0 & 1 & 0 & 0 & 0 & \\
\hline \multirow{3}{*}{ متعدد الأحجام } & 970 & 1 & 1 & 1 & 1 & 1 & 1 & 1 & 0 & 0 & \multirow{4}{*}{ OPW-11 } \\
\hline & 520 & 0 & 0 & 0 & 1 & 1 & 1 & 1 & 0 & 0 & \\
\hline & 385 & 1 & 0 & 1 & 0 & 1 & 1 & 1 & 0 & 0 & \\
\hline فريدة (مميزة) & 310 & 0 & 1 & 0 & 0 & 0 & 0 & 0 & 0 & 0 & \\
\hline
\end{tabular}

0 
Journal of Education and Science (ISSN 1812-125X), Vol: 30, No: 3, 2021 (104-116)

Special Issue for Proceeding of $3^{\text {rd }}$ National (1 ${ }^{\text {st }}$ international conference of biology) (ICBSUM 2021) 5, 6 July College of Education for Pure Science, University of Mosul, Mosul, Iraq.

اظهر البادئ OPA -4 العديد من الحزم ضمن هلام الأكاروز منها ما كان متباين 1320 , 386,479,581, 3090 و 70

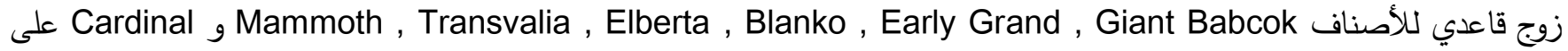
التوالي والاخر فريدة (مميزة) عند الحجوم الجزيئية 1620 , 1215 , 900 , 830 , 7703 , 640 , 605 , 505 , 410 و 312 زوج قاعدي على التوالي أيضا وتميز بارتباطه بالحمض النووي لجميع أصناف الخوخ الددروسة دون استثناء , وبلغ العدد الكلي للحزم المتضاعفة الناتجة منه 5 حزم وكانت نسبة التباين 68.8\% وبلغت قدرته التمييزية 12.9\% وبكفاءة 17.1\% الجدول (4).

جدول (4) يمثل الحزم المتضخمة مع أحجامها الجزيئية للبادئ (OPA-4)

\begin{tabular}{|c|c|c|c|c|c|c|c|c|c|c|}
\hline \multirow{2}{*}{ نوع الحزمة } & الحجم الجزيئي (زوج & \multicolumn{9}{|c|}{ |الأصناف } \\
\hline & 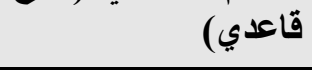 & 1 & 2 & 3 & 4 & 5 & 6 & 7 & 8 & 9 \\
\hline \multirow{10}{*}{ فريدة (مميزة) } & 1620 & 0 & 0 & 0 & 0 & 1 & 0 & 0 & 0 & 0 \\
\hline & 1215 & 0 & 0 & 0 & 0 & 0 & 0 & 0 & 1 & 0 \\
\hline & 900 & 0 & 0 & 0 & 0 & 0 & 0 & 0 & 1 & 0 \\
\hline & 830 & 0 & 0 & 0 & 0 & 0 & 0 & 0 & 1 & 0 \\
\hline & 770 & 0 & 0 & 0 & 0 & 0 & 0 & 0 & 0 & 1 \\
\hline & 640 & 0 & 0 & 0 & 0 & 0 & 0 & 0 & 0 & 1 \\
\hline & 605 & 0 & 0 & 0 & 0 & 0 & 0 & 0 & 1 & 0 \\
\hline & 505 & 0 & 0 & 0 & 0 & 0 & 0 & 0 & 1 & 0 \\
\hline & 410 & 0 & 0 & 0 & 0 & 0 & 0 & 0 & 0 & 1 \\
\hline & 312 & 0 & 0 & 0 & 1 & 0 & 0 & 0 & 0 & 0 \\
\hline \multirow{8}{*}{ متعدد الأحجام } & 1493 & 1 & 0 & 0 & 0 & 1 & 0 & 0 & 0 & 0 \\
\hline & 1320 & 0 & 0 & 0 & 0 & 1 & 0 & 0 & 0 & 1 \\
\hline & 890 & 0 & 0 & 1 & 1 & 1 & 0 & 1 & 0 & 0 \\
\hline & 581 & 0 & 1 & 0 & 1 & 0 & 1 & 0 & 0 & 0 \\
\hline & 479 & 0 & 0 & 1 & 1 & 0 & 1 & 0 & 0 & 0 \\
\hline & 386 & 0 & 0 & 0 & 0 & 0 & 1 & 1 & 0 & 0 \\
\hline & 230 & 0 & 1 & 1 & 0 & 0 & 1 & 0 & 0 & 0 \\
\hline & 70 & 0 & 1 & 1 & 0 & 0 & 1 & 0 & 0 & 0 \\
\hline
\end{tabular}




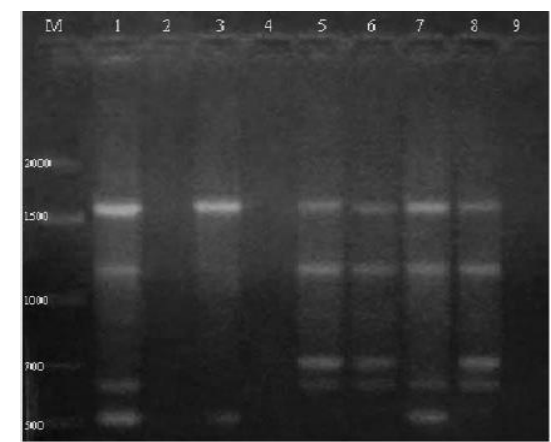

OPH-13

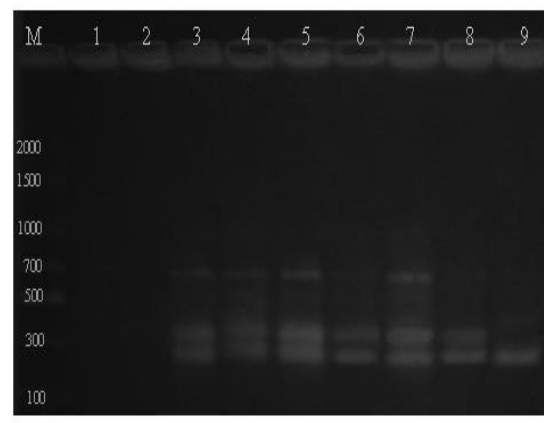

OPW-13

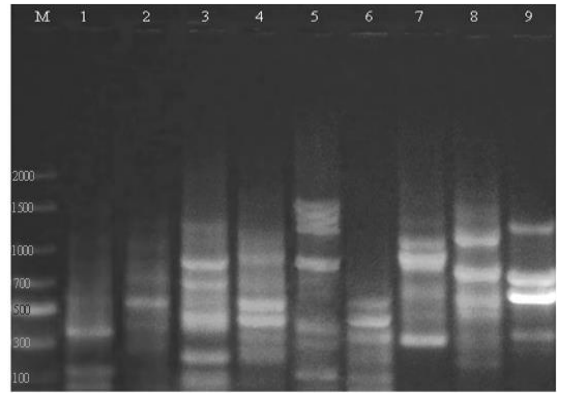

OPA-4

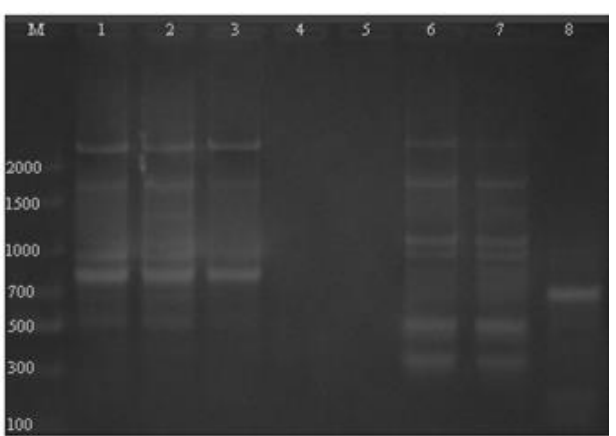

OPH-14

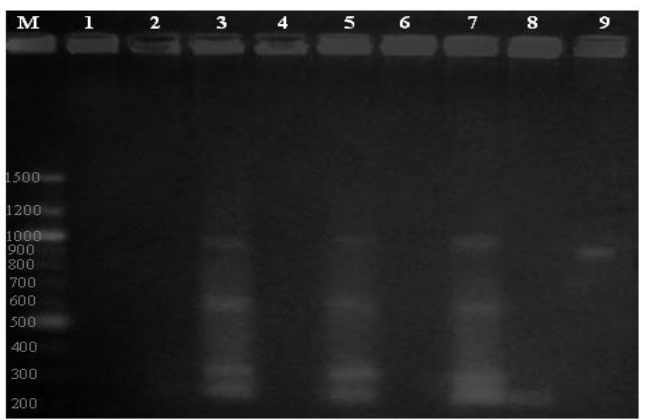

OPA-1

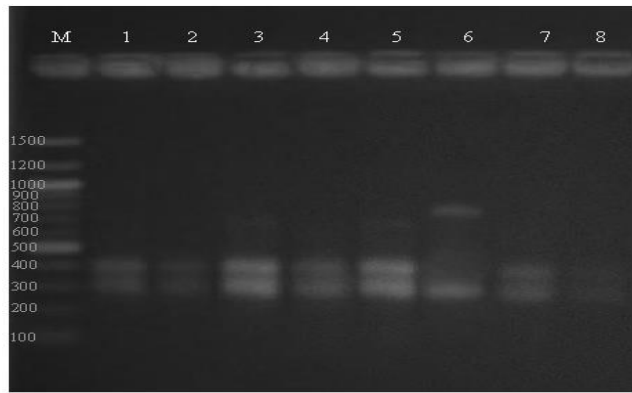

OPA-13

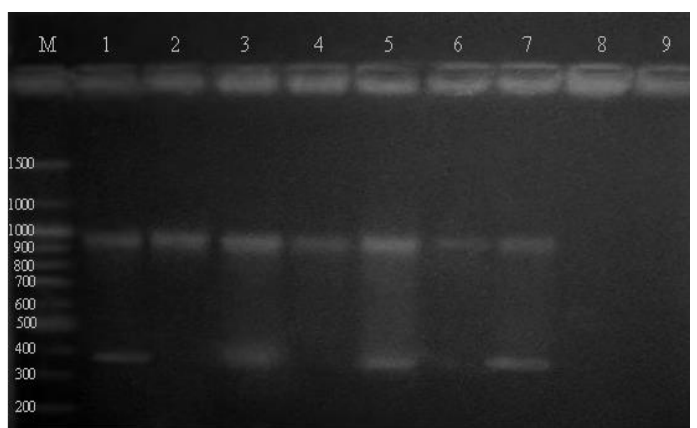

OPH-17

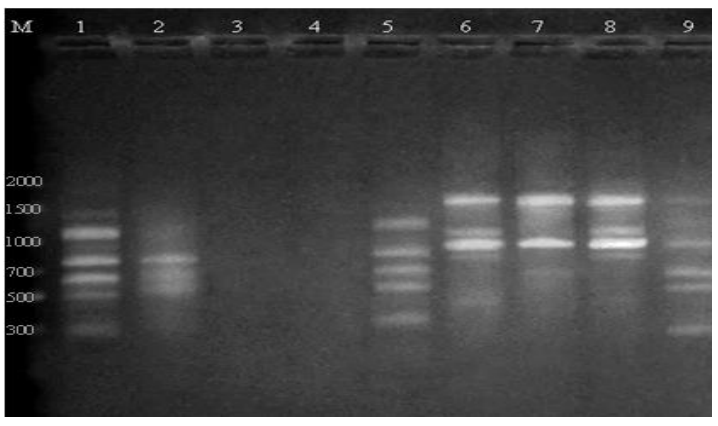

OPA-2

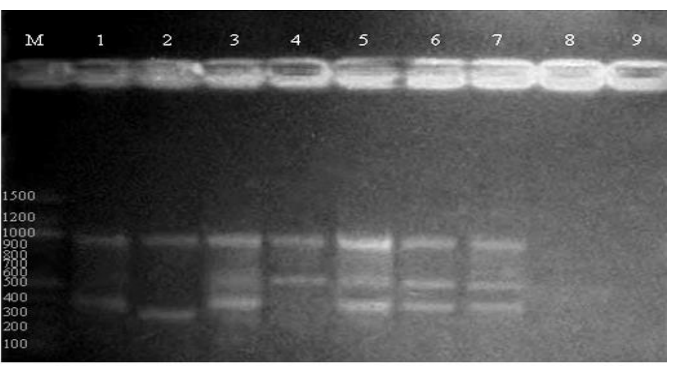

OPW-11

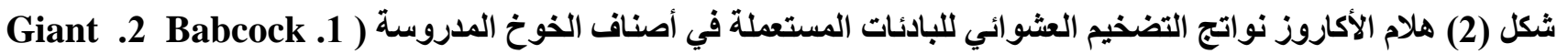
.9 Mammoth .8 Transvalia .7 Elberta .6 Blanko .5 Early Grand .4 Novadona .3 Babcok Cardinal ) و المسار M يمثل الاليل الحجمي (100 زوج قاعدي) . 
Journal of Education and Science (ISSN 1812-125X), Vol: 30, No: 3, 2021 (104-116)

Special Issue for Proceeding of $3^{\text {rd }}$ National (1'st international conference of biology) (ICBSUM 2021) 5, 6 July College of Education for Pure Science, University of Mosul, Mosul, Iraq.

UPGMA من خلا إدراج مخرجات النتائج الرقمية التي تم تمثيلها بالرمز 1 لوجود الحزمة و 0 لفقدان الحزمة ضمن برنامج

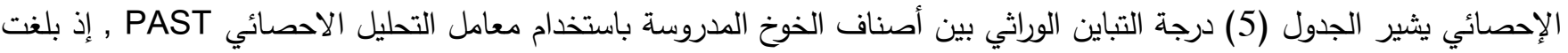
أعلى قيمة Transvalia في حين أن أقل قيمة كانت 0.72641 ضمن الصنير 0.108 ضمن الصنف Cradinal وتراوحت قيم باقي الأصناف بينهما , وهذا جاء متوافقة مع نتائج الدراسة الحالية عند المستوى الجزيئي التي أظهرت تباعد وراثي واضح للصنفين Cardinal , ومتثنقة لما أثار إليه [2] أن بادئات الـ RAPD تعد أدوات مهمة جدا في معرفة وتحديد التثابه الوراثي بين أشجار الفاكهة وتستخدم هذه البادئات بكثرة مع أشجار الخوخ والمشش , فضلا عن دراسة [3] التي أكدت على إستخدام بادئات الـ RAPD لتعريف وتحديد التتوع الوراثي والعلاقات الوراثية بين 28 صنفا من الخوخ.

جدول (5) مصفوفة التثابه بين أصناف الخوخ P.persica المدروسة بالاستناد الى معاملات التشابه وفق PAST

\begin{tabular}{|r|r|r|r|r|r|r|r|r|r||}
\hline & $\mathbf{1}$ & $\mathbf{2}$ & $\mathbf{3}$ & $\mathbf{4}$ & $\mathbf{5}$ & $\mathbf{6}$ & $\mathbf{7}$ & $\mathbf{8}$ & $\mathbf{9}$ \\
\hline $\mathbf{1}$ & 0.00000 & & & & & & & & \\
\hline $\mathbf{2}$ & 0.61738 & 0.00000 & & & & & & & \\
\hline $\mathbf{3}$ & 0.52174 & 0.52907 & 0.00000 & & & & & & \\
\hline $\mathbf{4}$ & 0.22857 & 0.34483 & 0.51429 & 0.00000 & & & & & \\
\hline $\mathbf{5}$ & 0.37037 & 0.29167 & 0.66667 & 0.51163 & 0.00000 & & & & \\
\hline $\mathbf{6}$ & 0.54167 & 0.52381 & 0.58333 & 0.46649 & 0.60714 & 0.00000 & & & \\
\hline $\mathbf{7}$ & 0.56601 & 0.36364 & 0.72641 & 0.41026 & 0.62069 & 0.65385 & 0.00000 & & \\
\hline $\mathbf{8}$ & 0.28571 & 0.16667 & 0.23811 & 0.19355 & 0.32067 & 0.45455 & 0.43478 & 0.00000 & \\
\hline $\mathbf{9}$ & 0.12121 & 0.11869 & 0.17290 & 0.19067 & 0.19756 & 0.11429 & 0.10811 & 0.13793 & 0.00000 \\
\hline
\end{tabular}

من خلال التحليل العنقودي Cluster Multivariate لتحديد طبيعة العلاقة الوراثية أظهرت شجرة التباين الوراثي الاصناف الخوخ Elberta , Blanko, Early Grand, Novadona , Giant Babcok , Babcock الدروسة مجموعة رئيسية شملت الأصناف

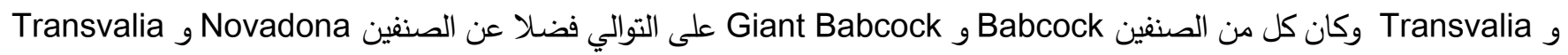
على التوالي الأكثر قرابة مع بعضها , وهذا دليل الى وجود درجة تثابه أعلى ضمن المادة الوراثية من الأصناف الأخرى والتي تستند

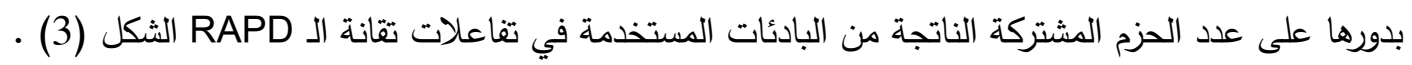




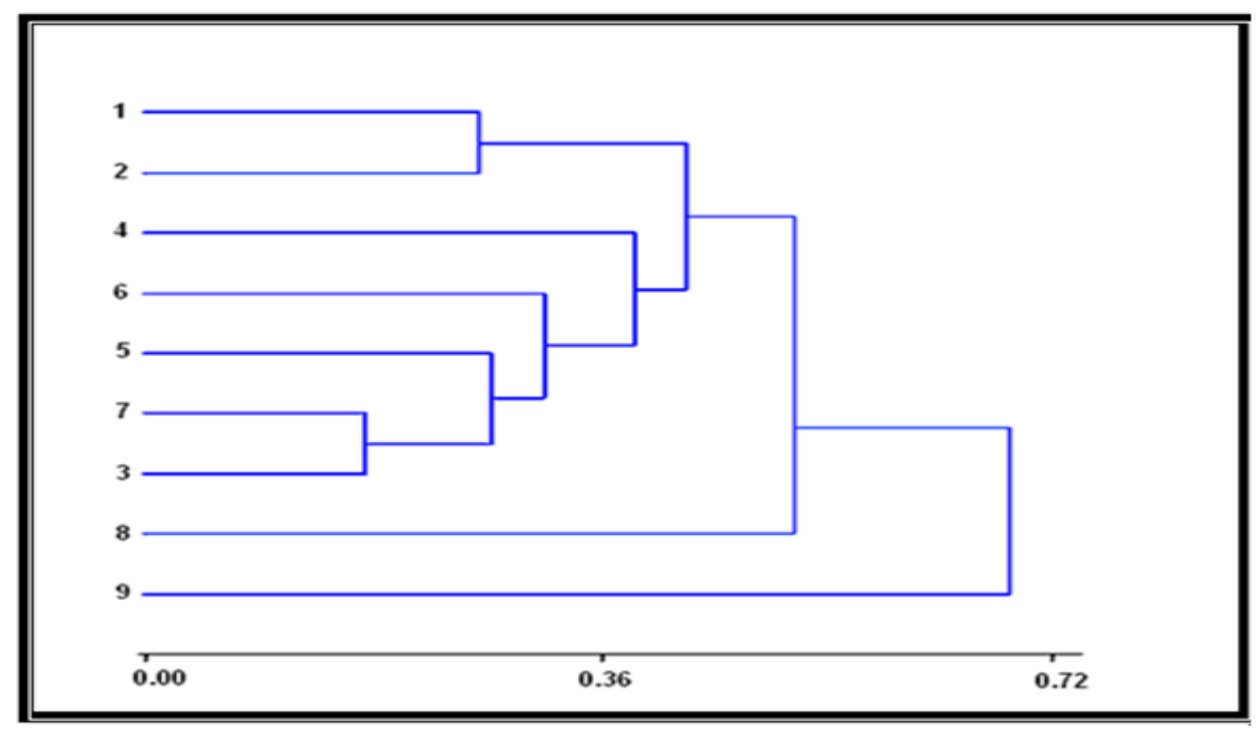

شكل (3) شجرة التباين الوراثي Pendogram لأصناف الخوخ P.persica قيد الدراسة ناتجة عن تحليل بيانات الـ PAPD وفق .PAST

\section{.1 )Babcock . 2 Giant Babcok.3 Novadona .4 Early Grand.5 Blanko .6 Elberta .7 Transvalia .8 Mammoth .9 Cardinal. (}

\section{المناقشة Discussion}

إن الإختلاف في أنواع وأعداد وحجوم حزم التضخيم لأصناف الخوخ قيد الدراسة قد يعود سببه الى قدرة البادئ على تحديد وإيجاد مواقع إرتباط له يتتاسب مع حجم معين من المادة الوراثية ضمن الحمض النووي للنباتات المدروسة وهذا يدل بدوره على وجود تباين وراثي بين الأصناف إعتمادا على تسلسل القواعد النيتروجينية للحمض النووي , أو قد يفسر على أساس حدوث طفرة ضمن الحمض النووي للأصناف المدروسة إما بالحذف أو الإستبدال أو الإضافة لأحد النيوكليوتيدات وهذا ما أكده [17] •

إن التغايرات الظاهرة فيما بين الأصناف ربما يرجع الى تراكم الطفرات الجسمية بفعل العوامل الداخلية الوراثية خلال فترة النمو الخضري للنبات كما إن تفاعلات الـ RAPD تتصف بحساسيتها لأي تغيير في مكونات تفاعلاتها لذلك يصعب إعادتها والحصول على نفس النتيجة لأن نتائجها تتأثر بتغير تراكيز مكونات التفاعل والظروف المحيطة وإن بعض البادئات المستخدمة أعطت حزمة فريدة لعدد من الأصناف ويعد ظهور الحزمة الفريدة أو (المميزة) Unique band من أهم الصفات التشخيصية المعتمدة في تمييز الأنواع والأصناف , إذ أن ظهور تلك الحزمة في نوع معين يدل على وجود ذلك التسلسل ضمن الحمض النووي المجيني لذلك الصنف دون الأصناف الأخرى قيد الدراسة [14]. ويدعى غياب الحزمة العامة (الرئيسية) Main band) لصنف معين دون غيره من الأصناف المدروسة بالحزمة الغائبة (Absent) وهذا الغياب يعد بمثابة دليل التمييز لذلك الصنف [18] . ويلاحظ من نتائج هذه الدراسة أنها قد ساعدت في تشخيص وتحديد درجة القرابة الوراثية بين اصناف الخوخ المدروسة ويمكن التوسع مستقبلا في دراسة هذه الاصناف وأصناف أخرى وتكوين خرائط وراثية لكل منها Amplified fragment length polymorphism و Site Specific Recombines (SSR) باستخدام تقانات احدث مثل تقانة 
References

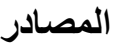

[1] Al-Rawi, Ali and Al- Duri, Aadel. (2000). Fruits Production, Books home for printing and distribution, Mosul University. (in Arabic)

[2] Patrol researches institute. (2003). Production of Peach in Egypt, Agricultural research center, Central Administration of Agricultural Guidance in the Ministry of Agriculture and Land Reclamation, Egypt. (in Arabic)

[3] Yaman, K.; Rawasut, A.; Yamak, G. and Hanjo, H.(2004). Relationship between chilling and heat requirement for flowering in ornamental Reseaches. J. Jap. Soc. Hort. Sci. 73 (6): 519-523.

[4] Wunsch, A. and Hormaza, J.J. (2002). Cultivar identification and genetic fingerprinting of temperature fruit tree species using DNA markers. J. Euphytica. 125: 59-67.

[5] Raddova, J.; Baranck, M.; Oukropec, I. and Vanchhun, M. (2003). RAPD analysis of peach with in Czech National collection. Czech J. Genet. 39(4):113-119.

[6] Mir, A. and Nabulsi, I. (2005). Genetic diversity of almonds (Prunus dulcus) using RAPD technique. Scientia Hort. cultivars 98:461-471.

[7] Oliveira, C.M.; Mota, M.; Monte-corvo, L.; Goulao, L. and Silva, D.M .(1999). Molecular typing based on RAPD markers. Sci .Hort. 79:163- 174.

[8] Landry, B.S.; Li, R.Q.; Cheung, W.Y. and Granger R.L.(1994). Phylogeny analysis of 25 apple rootstocks using RAPD markers and tactical gen tagging. Theor. Appl. Genet. 89: 847-852.

[9] Cipriani, G; lot, G.; Huarg, W.G.; Mavrazo, M.T.; Peterlunger, E. and testolin, R. (1999). AG/6T and AG/CT Microsatelite repeats in peach Prunus persica (L.) Batsch: Isolation, characterization and crossspecies amplification in Prunus. Theor. APP. Genet. 99:65-72.

[10] Weigand, F.; Baum, M. and Udupa, S. (1993). DNA Molecular marker techniques, technical manual, No. 20. Introductional center for agricultural research in the dry area. Aleppo, Syria.

[11] Maniatis , T. ; Fritsch , E. F. and Sambrook , J. (2000). In vitro Application of DNA by the polymers Chain Reaction, in Molecular cloning : A Laboratory Manual , 2d ed. Cold spring Harbor Laboratory press , New York, USA, pp. 691.

[12] Williams, C.E. and St-Clair, D.A. (1993). Phonetic relationships and level of variability detected by restriction fragment length polymorphism and random amplified DNA analysis of cultivated and wild accessions of Lycopersican esculentum. Genome .36: 619-930.

[13] Øyvind Hammer. (2009). PAST, PAlenological Statistics. Version1.94b, Reference manual, Natural History Museum, University of Oslo.

[14] Ercisly, S.; Agar, G.; Yildirim, N.; Esitkrn, A. and Orhan, E. (2009). Identification of apricot cultivars in Turkey Prunus persica (L.) using RAPD markers. J. Romanian Biotechnol let. 14 (4): 4582-4588. 